\title{
El principio de "smart regulation" en la normativa urbanística y de ordenación del territorio
}

\author{
María Teresa Barranco Pérez \\ Abogada \\ Personal Investigador en Formación (PIF) \\ Universidad de Málaga
}

SUMARIO: I. INTRODUCGIÓN AL CONGEPTO DE "SMART REGULATION". II. IMPLEMENTACIÓN DEL CONCEPTO DE "SMART REGULATION" EN ESPAÑA. III. LA MEMORIA DEL ANÁLISIS DE IMPACTO NORMATIVO: Especial referencia al Real Decreto 931/2017, de 27 de Octubre, por el que se regula la Memoria del Análisis de Impacto Normativo. IV. LA IMPORTANGIA DE UNA REGULACIÓN INTELIGENTE PARA LA TRANSFORMACIÓN URBANÍSTICA DEL TERRITORIO: ESPECIAL REFERENCIA A LA AUTONOMÍA LOCAL. V. EL PRINCIPIO DE "SMART REGULATION" EN LA ORDENAGIÓN URBANÍSTICA Y TERRITORIAL. VI. CONSIDERAGIONES PREVIAS A LA ELEGCIÓN DEL MODELO TERRITORIAL. VII. INVESTIGAGIÓN EXPLORATORIA Y BIBLIOGRÁFICA.

RESUMEN: Con carácter previo a la entrada en vigor de una norma urbanística o de ordenación del territorio, debemos ser conscientes del efecto y las consecuencias tanto sociales como económicas que su aplicación va a generar y que condicionará no sólo la viabilidad de la norma en cuestión sino el desarrollo futuro del territorio donde se aplique. Es por ello que dicha norma no sólo tiene que ser más eficaz y eficiente en la consecución de los objetivos de interés público que se persiguen sino que tiene que ser capaz de aportar un verdadero valor añadido, así como provocar beneficios amplios a costes mínimos, respetando los principios de subsidiariedad y proporcionalidad con el fin de lograr un marco reglamentario simple, claro, estable y predecible, tanto para las empresas como para los ciudadanos, esto es, conseguir una "regulación inteligente" (Smart regulation) en la ordenación del territorio.

PALABRAS CLAVES: regulación inteligente, urbanismo, ordenación del territorio, viabilidad, desarrollo

Recibido: 26/03/2018.

Aceptado: 9/11/2018. 
ABSTRACT: Prior to the approval and application of an urban or territorial planning, we must be aware of their effects and the social and economic consequences that its application will generate. That will condition not only the viability of the law or planning in question but also the future development of the territory where it is applied. That is why it must not only be more effective and efficient in achieving the public interest objectives pursued, but it must be able to provide real added value, as well as bring about wide benefits at minimum costs, respecting the principles of subsidiarity and proportionality in order to achieve a simple, clear, stable and predictable regulatory framework for both companies and citizens, that is, to achieve "smart regulation" in territorial planning.

KEY WORDS: Smart regulation, urban and territorial planning, viability, development.

\section{INTRODUCGIÓN AL CONCEPTO DE "SMART REGULATION"}

El principio de "Smart Regulation" o de Regulación Inteligente deviene, en un primer momento, de otro concepto, el de "Better Regulation" o Buena Regulación, propiciatorio de la desregulación y la simplificación de las normas, aunque va un paso más allá, inspirándose en la creación de un marco regulatorio de calidad, basado en el conocimiento preciso de todos los elementos existentes y de la repercusión real de la normativa a aprobar no sólo para alcanzar los objetivos pretendidos sino para desarrollar, igualmente, la actividad económica. Para ello es esencial el conocimiento de "buenas prácticas" existentes en el ámbito normativo estudiado y el contacto directo con el sector privado, a efectos de identificar en qué casos es necesario una solución reguladora y qué forma debe adoptar ésta para favorecer e incentivar la creación de riqueza.

Los esfuerzos de la Unión Europea para mejorar y simplificar el complejo entramado normativo comenzaron a principios de 1980. Ya en 1985 se adoptaron determinadas medidas en torno a la constitución del Mercado Único Europeo y en el Consejo Europeo de Edimburgo de 1992, se asumió, como prioridad principal, la simplificación y mejora del escenario normativo de la Unión Europea.

El Tratado de Maastricht, en 1993, dio especial relevancia a los principios de subsidiariedad y proporcionalidad normativa y, posteriormente, un Informe anual de la Comisión al Consejo Europeo sobre "Better law-making" marcaba las pautas para su desarrollo'.

1 "Declaration 39 on the quality of the drafting of Community legislation", incluida en el Acta Final del Tratado de Amsterdam de 1997. 
En el año 2000, la Unión Europea se propuso un nuevo objetivo para esa década, el de preparar la transición a una economía competitiva, dinámica y basada en el conocimiento, y a la que se denominó la Estrategia de Lisboa. La consecución de este objetivo dependía, entre otros factores, de la creación de un escenario normativo claro, simple, funcional y efectivo y para preparar las correspondientes recomendaciones en esta área, se constituyó un grupo de expertos de la Comisión Europea y de los Estados miembros, cada uno de acuerdo a sus respectivas competencias, a cargo de Dieudonné Mandelkern. En noviembre de 2001 se presenta el conocido como "Mandelkern Report", que contenía una batería de propuestas con plazos y fechas límites para la mejora de la calidad y la simplificación de las normas así como para la adopción de medidas de reforma legal en los Estados miembros, incluyéndose en esta simplificación la reforma de las Administraciones Públicas. Para ello, se amplió el Programa SLIM (Simpler Legislation for the Internal Market), que había venido operando desde $1997^{2}$.

En 2005 se produce un cambio en el contenido de las políticas destinadas a mejorar el marco normativo de la Unión Europea por cuanto, tras el análisis de los textos normativos europeos se observa una falta de coherencia y de consistencia en los mismos que generan una falta de claridad en su aplicación e interpretaciones divergentes por parte de los Estados miembros. Así, y a partir de ese año, las resoluciones y políticas en torno al concepto de "Better Regulation" devienen en "Smart Regulation" por cuanto no se trata sólo de mejorar el marco normativo existente sino de dar un paso más y desarrollar dicho marco normativo de una forma inteligente, eficaz y clara ${ }^{3}$.

Fruto de esta evolución es la Directiva de Servicios Europea 2006/123/CE, de 12 de Diciembre, relativa a los servicios en el mercado interior, enmarcada en la Estrategia Europea 2020, y encaminada a la mejora del funcionamiento del Mer-

2 Para asegurar el éxito y la fortaleza de esta iniciativa, la Comisión Europea presentó en Junio de 2002 una serie de medidas en el campo de la "Better Regulation”, COM (2002) 278 final, y una propuesta de reducción del volumen normativo en 2003, COM/2003/007 1 Final.

3 Así, la Comisión Europea emite varias Comunicaciones al respecto con objeto de guiar y orientar la implementación del concepto de "Smart Regulation" en aquellos sectores donde se ha detectado mayor confusión y diferencias interpretativas A modo de ejemplo, "Communication from the Commission on Impact Assessment", $\operatorname{COM}(2002)$ 276, de 5 de junio de 20025, "Communication from the Commission to the Council and the European Parliament 'Better Regulation for Growth and Fobs in the European Union', COM (2005) 97, SEG (2005) 175, de 16 de Marzo de 2005, o “Impact Assessment Guidelines", SEG (2005) 791, de 15 de Junio de 2005, actualizado en Maro de 2006.

En el mismo sentido el estudio realizado para la 44 reunión de Directores Generales responsables de las Administraciones Públicas de los Estados miembros de la UE, Milestones on the way to Better Regulation at the European Union Level, KONZENDORF, G., WORDELMANN, P., BÖLCK, S. y VEIT, S. Luxemburgo, Junio 2005. 
cado Único de Servicios, que propugnaba en sus Considerandos 42 y siguientes, la aplicación de principios de simplificación administrativa para evitar la complejidad, extensión e inseguridad jurídica de los procedimientos administrativos en el acceso a las actividades de servicios, la eliminación de redundancias y costes excesivos, el derecho a la información, el establecimiento de procedimientos y trámites por vía electrónica y las ventanillas únicas administrativas. Tal es la importancia que la propia directiva asigna a la simplificación administrativa como elemento esencial para la mejora de la calidad de los servicios en el espacio europeo, que le dedica un capítulo completo.

Así, el capítulo segundo de dicha norma, artículos 5 a 8, comienza con el mandato a los Estados miembros, de verificar los procedimientos y trámites aplicables al acceso a una actividad de servicios y a su ejercicio, y la obligación de simplificarlos en el caso de que tanto los procedimientos como las formalidades requeridas no sean lo suficientemente simples (art. 5.1).

En España, la transposición de los artículos incluidos en este capítulo segundo se realizó a través de la Ley 11/2007, de 22 de Junio, de acceso electrónico de los ciudadanos a los Servicios Públicos, en relación a la Ventanilla única, el Derecho de Información y los procedimientos por vía electrónica ${ }^{4}$.

Con motivo de la evaluación de la implementación de la "Directiva de Servicios" en los estados miembros, en la Comunicación de la Comisión al Parlamento Europeo, al Consejo, al Comité Económico y Social Europeo y al Comité de las Regiones denominada "Hacia un mejor funcionamiento del Mercado Único de Servicios, partiendo de los resultados del proceso de evaluación recíproca de la Directiva de Servicios" (COM (2010) 2020 Final) se indica que, siendo los servicios la fuerza motriz de la economía de la Unión Europea, es esencial contar con un mercado único de servicios que funcione bien y esté verdaderamente integrado, debiendo aprovechar el enorme potencial que ofrece dicho mercado único como catalizador para generar crecimiento sostenible y empleo, ampliar las posibilidades de elección de los consumidores y abrir nuevas oportunidades a las empresas.

Especialmente importante es, en este sentido, el compromiso del Consejo de la Unión Europea que, a mediados del 2012 inició un periodo de consultas públicas con objeto de reunir las valoraciones de todos los interesados, culminando, el 19 de

4 Posteriormente, la Disposición Adicional Tercera de la Ley 17/2009, de 23 de Noviembre, sobre el libre acceso a las actividades de servicios y su ejercicio (una de las dos normas, junto con la Ley 25/2009, por las que el Estado español procedió a la transposición de la Directiva de Servicios), dispone la creación de un Comité transversal en el que participen todas las Administraciones Públicas, y cuyos objetivos son los de facilitar la tramitación de las actividades de servicios y la correcta transposición de la Directiva de Servicios por parte de todos los operadores administrativos. 
Mayo de 2015, con la Comunicación de la Comisión al Parlamento Europeo y al Consejo sobre la Propuesta de Acuerdo Interinstitucional sobre la mejora de la legislación (COM 2015, 216 final $)^{5}$. En ella, las tres instituciones comunitarias reconocen su responsabilidad compartida de mejorar la legislación, de velar por que la legislación de la Unión se centre en aquellos ámbitos en los que tenga mayor valor añadido, sea lo mas eficiente y eficaz posible, comporte la menor carga posible para las partes interesadas y esté concebida para facilitar su transposición y su aplicación práctica y para fortalecer la competitividad y la sostenibilidad de la economía de la Unión. Y, de hecho, recuerdan la obligación de la Unión de legislar sólo cuando sea necesario, de conformidad con los principios de subsidiariedad y proporcionalidad conforme al artículo 5 del tratado de Funcionamiento de la Unión Europea.

Reflejo de todo ello ha sido la creación de un grupo operativo ("task force") sobre el escenario 4 definido en el Libro Blanco sobre el futuro de Europa ${ }^{6}$ y denominado "Hacer menos pero de forma más eficiente" ("Doing less, More efficiently"). Este Grupo operativo, creado oficialmente el 14 de Noviembre de 2017, bajo la dirección del primer vicepresidente Frans Timmermans, está compuesto por tres miembros de los Parlamentos Nacionales de Austria, Bulgaria y Estonia, y tres miembros del Comité Europeo de las Regiones, aunque sin ninguna representación del Parlamento Europeo, teniendo, entre sus tareas principales la de estudiar cómo aplicar mejor los principios de subsidiariedad y proporcionalidad en el trabajo de las instituciones de la Unión (en particular en lo que respecta a la preparación y aplicación de la legislación y las políticas) y la de detectar maneras de mejorar la participación y seguimiento de las políticas de la Unión.

Como resultado del trabajo conjunto y las aportaciones de ciudadanos y otros agentes de la sociedad civil, con fecha de 10 de Julio de 2018 se hizo público el Informe al Presidente de la Comisión Europea del Grupo Operativo sobre Subsidiariedad, Proporcionalidad y "Hacer menos pero de forma más eficiente"”. En dicho Informe, el grupo operativo alcanza varias conclusiones generales y presenta nueve recomendaciones junto con medidas concretas, dirigidas a los Parlamentos Nacionales, a las Administraciones Locales y Regionales, al Parlamento Europeo, al Consejo, al Comité Europeo de las Regiones y a la Comisión Europea.

5 En ella, se reafirma la importancia de "la transparencia del proceso legislativo, la legitimidad democrática, la subsidiariedad, la proporcionalidad, la seguridad jurídica y la sencillez, claridad y coherencia en la redacción de la legislación".

6 http://ec.europa.eu/commission/white-paper-future-europe_es

7 https://ec.europa.eu/commission/files/report-task-force-subsidiarity-proportionality-and-doing-less-more-efficiently 
Partiendo de que es necesaria una nueva forma de trabajar para mejorar los actuales procesos de elaboración de políticas y para posibilitar que la Unión utilice sus recursos de manera más eficiente para permitir a las administraciones locales y regionales y a los Parlamentos nacionales realizar una contribución más eficaz a la elaboración de políticas, al diseño de nueva legislación y a la garantía del respeto de los principios de subsidiariedad y proporcionalidad, proponen la utilización de una plantilla tipo para que la Comisión Europea, los Parlamentos nacionales y regionales, el Comité Europeo de las Regiones, el Parlamento Europeo y el Consejo puedan evaluar de manera más coherente la subsidiariedad y la proporcionalidad en todo el proceso de toma de decisiones.

En palabras del Presidente del Grupo Operativo, Frans Timmermans, "En la actualidad, contamos con 41 cámaras parlamentarias nacionales, 74 asambleas legislativas regionales, alrededor de 280 regiones, y 80.000 administraciones locales. Todas ellas participan directamente en la aplicación sobre el terreno de las políticas de la UE. Deberían escucharse sus preocupaciones y experiencia práctica de manera más sistemática si queremos políticas que funcionen y a la vez respeten el carácter y la identidad de nuestras naciones, regiones y municipios. Espero que al ofrecer información más significativa sobre cómo se hacen las cosas, nuestros Parlamentos nacionales y las administraciones locales y regionales puedan también ser embajadores y defensores más efectivos de la Unión europea"8.

Una de las conclusiones de dicho informe se centra en la necesidad de desarrollar un mecanismo que identifique y evalúe la legislación desde la perspectiva de la subsidiariedad, la proporcionalidad, la simplificación, la densidad legislativa y el papel de las administraciones locales y regionales.

El Estado español implementa por vez primera este concepto en la Ley 2/2011, de 4 de Marzo, de Economía Sostenible, donde se establece con carácter general un marco para el desarrollo de las políticas de mejora regulatoria en todas las Administraciones Públicas y se otorga un papel destacado al análisis de impacto normativo. Los cuatro elementos que sustentan este marco de mejora normativa se resumen en los siete criterios y/o directrices que deben seguir las políticas públicas, los instrumentos a disposición de las Administraciones para su ejecución, los objetivos de adaptación de la normativa existente y los mecanismos para su seguimiento.

En un primer lugar nos encontramos el criterio de la Necesidad, por el que se establece que las iniciativas normativas deben estar justificadas por razones de interés general, que hagan aconsejable contar con una regulación específica.

8 Prólogo del Presidente del Grupo Operativo. Informe de 10 de Julio de 2018. 
Por otra parte, y en virtud de la Proporcionalidad, la regulación debe elegir el instrumento más adecuado, frente a soluciones alternativas posibles, ya sean de carácter normativo u otras, para la consecución del objetivo que se persigue. Esto es, si la premisa es que la regulación debe ser la mínima posible para la consecución de los fines que se pretenden, la regulación inteligente debe confirmar que no existen otras medidas menos restrictivas o distorsionantes de las decisiones privadas que permitan obtener el mismo resultado.

El tercer criterio para la regulación inteligente será el de Seguridad Jurídica, entendiéndose por tal que las propuestas regulatorias deben fomentar un entorno de certidumbre que favorezca la adopción de las decisiones económicas por parte de los agentes y que mantenga la coherencia con el resto del ordenamiento jurídico-económico.

En cuarto y en quinto lugar, por su obviedad, la Simplicidad, en el sentido de que debe facilitarse el conocimiento y la comprensión del marco normativo con claridad en sus disposiciones y sencillez en su leguaje, y la Eficacia, identificando objetivos claros y directos para evitar cargas innecesarias y accesorias para su consecución.

Los dos últimos criterios recogidos en la Ley 2/2011, de 4 de Marzo, de Economía Sostenible aluden a la rendición de cuentas por parte del regulador: El de Transparencia en cuanto a los objetivos y justificación de la regulación y el de Accesibilidad de la normativa con objeto de favorecer la participación activa de los sectores y colectivos implicados o afectados por la regulación en su proceso de elaboración (en particular mediante mecanismos de consulta).

En resumen, y como la propia Ley recoge en su Preámbulo, se persigue la promoción de un marco normativo "fácilmente accesible por los ciudadanos y agentes económicos, posibilitando el conocimiento rápido y sencillo de la normativa vigente que resulte de aplicación y sin más cargas administrativas para los ciudadanos y empresas que las estrictamente necesarias para la satisfacción del interés general".

Sobre esta base, la Ley de Economía Sostenible recoge los instrumentos a disposición de las Administraciones Públicas para la mejora de la regulación y la aplicación del Principio de Regulación Inteligente, tales como los instrumentos de análisis previo de iniciativas normativas para garantizar que se tengan en cuenta los efectos de cualquier tipo que éstas produzcan, con objeto de evitar a ciudadanos y empresas costes innecesarios o desproporcionados en relación al interés general perseguido.

También se da especial relevancia a los procedimientos de consulta pública a los efectos de prestar la máxima atención en la elaboración de proyectos normativos, 
fomentando la participación de los interesados con el fin de mejorar la calidad de la norma.

Tras todo este análisis preventivo, la Ley de Economía Sostenible también recoge la previsión de procedimientos de evaluación a posteriori de la actuación normativa, con objeto de revisar aquella ya existente con expresa indicación a las Administraciones Públicas de la necesidad de revisión periódica de la normativa vigente para adaptarla a los Principios de Regulación Inteligente.

A lo expuesto, hay que añadir la regulación de la Memoria del Análisis del Impacto Normativo a través del Real Decreto 1083/2009, de 3 de Julio, pieza clave en el objetivo de mejora de la legislación desde la conciencia del papel que los ordenamientos jurídicos ostentan como motor del desarrollo económico sostenible, la competitividad y la creación de empleo y la Guía Metodológica para la elaboración de dichas Memorias, aprobada por Consejo de Ministros en Diciembre de 2009, que ha supuesto la sustitución de las conocidas "Memorias Económicas", prestando especial atención a la valoración del impacto económico de las propuestas normativas mas allá de la mera estimación del coste presupuestario.

Siguiendo esta línea, y tras la Creación de la Comisión para la reforma de las Administraciones Públicas aprobada mediante Acuerdo de Consejo de Ministros de 26 de Octubre de $2012^{9}$, el desarrollo de los Principios de Regulación inteligente se ha visto plasmado en la Ley 19/2013, de 9 de Diciembre, de transparencia, acceso a la información pública y buen gobierno o en la Ley 20/1013, de 9 de diciembre, de garantía de la unidad de mercado, si bien la más reciente es la Ley 39/2015, de 1 de Octubre, del Procedimiento Administrativo de las Administraciones Públicas, cuyo Preámbulo se remite al informe elaborado por la Comisión para la Reforma de las Administraciones Públicas en junio de 2013 partiendo del convencimiento de que una economía competitiva exige unas Administraciones Públicas eficientes, transparentes y ágiles y al Programa nacional de reformas de España para 2014 que recogía expresamente la aprobación de nuevas leyes administrativas como una de las medidas a impulsar para racionalizar la actuación de las instituciones y entidades del poder ejecutivo, mejorar la eficiencia en el uso de los recursos públicos y aumentar su productividad.

El texto viene a reconocer los defectos que tradicionalmente se han venido atribuyendo a las Administraciones españolas y que, si bien obedecen a varias causas, destaca entre ellas que el marco normativo en el que se ha desenvuelto la actuación pública ha propiciado la aparición de duplicidades e ineficiencias, con procedimien-

9 Su objetivo principal era la adaptación y modernización de las Administraciones Públicas al nuevo contexto social y hacer de las mismas un elemento práctico y dinámico de servicio útil y eficiente a los administrados. 
tos administrativos demasiado complejos que, en ocasiones, han generado problemas de inseguridad jurídica.

La ley 39/2015 de 1 de Octubre, del Procedimiento Administrativo de las Administraciones Públicas pretende, para superar estas deficiencias, realizar una reforma integral y estructural que permita ordenar y clarificar cómo se organizan y relacionan las Administraciones tanto externamente, con los ciudadanos y empresas, como internamente con el resto de Administraciones e instituciones del Estado.

En coherencia con este contexto, propone una reforma del ordenamiento jurídico público articulada en dos ejes fundamentales: las relaciones «ad extra» y «ad intra» de las Administraciones Públicas, constituyendo esta Ley el primero de estos dos ejes, al establecer una regulación completa y sistemática de las relaciones «ad extra» entre las Administraciones y los administrados, tanto en lo referente al ejercicio de la potestad de autotutela y en cuya virtud se dictan actos administrativos que inciden directamente en la esfera jurídica de los interesados, como en lo relativo al ejercicio de la potestad reglamentaria y la iniciativa legislativa. Queda así reunido en cuerpo legislativo único la regulación de las relaciones «ad extra» de las Administraciones con los ciudadanos como ley administrativa de referencia que se debe complementar con todo lo previsto en la normativa presupuestaria respecto de las actuaciones de las Administraciones Públicas.

Haciendo expresa referencia a la mejora de la producción normativa ("Better regulation" y "Smart regulation"), concluye que es necesario contar con una nueva regulación que, terminando con la dispersión normativa existente, refuerce la participación ciudadana, la seguridad jurídica y la revisión del ordenamiento ${ }^{10}$.

El segundo de los ejes referidos lo encontramos en la Ley 40/2015, de 1 de Octubre, del Régimen Jurídico del Sector Público. En su Preámbulo, al igual que en la norma anterior, se reconoce que las Administraciones Públicas, lejos de constituir un obstáculo para la vida de los ciudadanos y las empresas, deben facilitar la libertad individual y el desenvolvimiento de la iniciativa personal y empresarial. Para ello

10 Su Preámbulo reconocía que: "Con estos objetivos, se establecen por primera vez en una ley las bases con arreglo a las cuales se ha de desenvolver la iniciativa legislativa y la potestad reglamentaria de las Administraciones Públicas con el objeto de asegurar su ejercicio de acuerdo con los principios de buena regulación, garantizar de modo adecuado la audiencia y participación de los ciudadanos en la elaboración de las normas y lograr la predictibilidad y evaluación pública del ordenamiento, como corolario imprescindible del derecho constitucional a la seguridad jurídica. Esta novedad deviene crucial especialmente en un Estado territorialmente descentralizado en el que coexisten tres niveles de Administración territorial que proyectan su actividad normativa sobre espacios subjetivos y geográficos en muchas ocasiones coincidentes. Con esta regulación se siguen las recomendaciones que en esta materia ha formulado la Organización para la Cooperación y el Desarrollo Económicos (OCDE) en su informe emitido en 2014, Spain: From Administrative Reform to Continous Improvement" 
considera imprescindible establecer un marco normativo que impida la creación de órganos o entidades innecesarios o redundantes, y asegure la eficacia y eficiencia de los entes públicos, ejerciendo sobre ellos una supervisión continua que permita evaluar el cumplimiento de los objetivos que justificaron su creación, y cuestionar su mantenimiento cuando aquellos se hayan agotado o exista otra forma más eficiente de alcanzarlos.

Hay que apuntar que dicha regulación se ha visto afectada por la reciente Sentencia del Tribunal Constitucional núm. 55/2018, de 24 de Mayo, tras recurso de inconstitucionalidad 3628/2016 interpuesto por el gobierno de la Generalidad de Cataluña. Dicha Sentencia declara que el artículo 129 (Principios de Buena Regulación), salvo los párrafos segundo y tercero de su apartado cuarto, y los artículos 130 (Evaluación normativa y adaptación de la normativa vigente a los principios de buena regulación), 132 (Panificación Normativa) y 133 (Participación de los ciudadanos en el procedimiento de elaboración de normas con rango de ley o reglamentos) son contrarios al orden constitucional de distribución de competencias.

Así, en su Fundamento Jurídico 7 b) se especifica que los Estatutos de Autonomía reconocen la iniciativa legislativa a los gobiernos autonómicos, no a sus administraciones y que el ejercicio de la actividad legislativa por parte de las Comunidades Autónomas, en general, y la elaboración de anteproyectos de ley, en particular, quedan por completo al margen del artículo 149.1.18 CE en lo que se refiere tanto a las bases del régimen jurídico de las administraciones públicas como al procedimiento administrativo común. Por ello, considera que dichos artículos, al referirse al ejercicio por parte de los gobiernos nacional y autonómico, tanto de la potestad reglamentaria como de la iniciativa legislativa, invaden las competencias que las Comunidades Autónomas tienen atribuidas estatutariamente en orden a organizarse y regular la elaboración de sus leyes.

Tales circunstancias no conllevan la nulidad de los citados artículos, si bien, para remediar la invasión competencial señalada, se declara que estos preceptos son contrarios al orden constitucional de competencias y que, en consecuencia, no son aplicables a las iniciativas legislativas de las Comunidades Autónomas.

También declara esta Sentencia contrarios al orden constitucional de competencias los artículos 132 y 133, salvo el inciso de su apartado primero, "con carácter previo a la elaboración del proyecto o anteproyecto de ley o de reglamento, se sustanciará una consulta pública" y el primer párrafo de su apartado cuarto, en los términos de lo dispuesto en el Fundamento Jurídico 7 c).

En dicho apartado, y reiterando la STC 91/2017 (Fundamento Jurídico Sexto), se concluye que dicha declaración de invasión competencial tampoco conlleva la 
nulidad de los preceptos, habida cuenta de que los mismos se aplican en el ámbito estatal.

Con independencia de estas cuestiones competenciales analizadas por la jurisprudencia reciente, lo que resulta especialmente sorprendente, después de todo lo expuesto, es la inexistencia de estos Principios de Regulación Inteligente en la normativa urbanística y de ordenación territorial, eminentemente restrictiva, confusa y contradictoria, donde se impone al ciudadano y a los agentes económicos una serie de normas dispersas y de difícil entendimiento, en un modelo de ciudad o de región diseñado a través de Planes Generales de Ordenación Urbanística o de Ordenación del Territorio cuya tramitación es lenta, laboriosa y opaca, y que repercute directamente en el desarrollo económico de los municipios.

\section{LA MEMORIA DEL ANÁLISIS DE IMPACTO NORMATIVO: ES- PECIAL REFERENCIA AL REAL DECRETO 931/2017, DE 27 DE OCTUBRE, POR EL QUE SE REGULA LA MEMORIA DEL ANÁ- LISIS DE IMPACTO NORMATIVO}

El proceso de evaluación de impacto y sus valoraciones, se basan en el principio del análisis proporcionado al que nos hemos referido con anterioridad al hablar de las Recomendaciones del Informe de 10 de Julio de 2018, del Grupo operativo sobre Subsidiariedad, proporcionalidad y "hacer menos pero de forma más eficiente". Se trata de evaluar aquello que es importante para un expediente normativo concreto con carácter previo, de manera que el funcionamiento y el resultado de la legislación se compruebe antes de que se realicen propuestas para su modificación. Dicha evaluación deberá supervisar la eficacia, la eficiencia económica, la pertinencia, la coherencia y el valor añadido que dicha modificación pueda implicar.

La evaluación previa de las políticas públicas y del impacto normativo de las leyes, o evaluación ex-ante, es un factor fundamental para el éxito de las mismas y para la mejora de la calidad, la eficiencia y la eficacia de la intervención pública ${ }^{11}$. No sólo es necesario que, con carácter previo a la entrada en vigor de una norma, seamos conscientes del efecto y las consecuencias tanto sociales como económicas que su aplicación va a generar también es una responsabilidad directa de los órganos de la administración encargados de su tramitación y aprobación, y que condiciona la viabilidad de la norma en cuestión.

11 Así, FERNÁNDEZ DÍEZ-PICAZO, M. y MATEO FEITO, M., en su artículo "Evaluación de impacto normativo en España”, en Revista Presupuesto y Gasto Público, núm. 68 (2012), pp. 111-124, Secretaría de Estado de Presupuestos y Gastos, Instituto de Estudios Fiscales (2012), reconocen que "la evaluación previa, o análisis de impacto normativo, tiene un papel central en las políticas de mejora regulatoria por su contribución a la calidad del proceso de toma de decisiones". 
Esta evaluación o análisis de impacto normativo tiene como objetivo identificar y ordenar toda la información relevante para valorar una iniciativa legislativa y así facilitar la toma de decisiones sobre la misma, y es uno de los pilares fundamentales de la Política de "Smart Regulation" de la Comisión Europea ${ }^{12}$.

Resulta obvio que estos análisis o evaluaciones previas a la entrada en vigor de una norma no sólo tienen un carácter preventivo sino eminentemente práctico. El hecho de estudiar la implicación directa e indirecta de la regulación proyectada en el sector de población al que irá dirigida, o sus costes y "beneficios" contribuyen a evidenciar la viabilidad (o no) de la norma influyendo en el crecimiento económico de la zona o región a largo plazo.

En la última década han venido aprobándose un conjunto de medidas para impulsar la mejora de la regulación y actuación de la Administración ${ }^{13}$, en la línea seguida tanto por la Unión Europea como por la Organización para la Cooperación y el desarrollo Económico (OCDE), que defienden una regulación inteligente que permita dinamizar la actividad económica, simplificar procesos y reducir cargas administrativas, siendo las memorias del análisis del impacto normativo, como evaluación "ex ante", los instrumentos claves para alcanzar dichos objetivos14.

Como hemos indicado en el epígrafe anterior, la Comisión Europea publicó el 19 de Mayo de 2015 el documento "Better Regulation Package", un paquete de mejoras normativas que incluye una serie de herramientas tales como la identificación de los objetivos de las políticas públicas, la evaluación respecto si la normativa es o no necesaria, cómo puede ser más eficaz y eficiente para lograr los objetivos propuestos y la consideración de alternativas y ventajas de distintos enfoques en orden a la identificación del más adecuado.

A efectos prácticos, desde el lanzamiento del Programa de Adecuación de la normativa (REFIT) con objeto de simplificar la legislación vigente por parte de la Comisión Europea se han emprendido casi 200 iniciativas de reducción de cargas y simplificación normativa: Nuevas normas en materia de contratación electrónica (para reducir costes de contratación en un 20\%), un plan de acción sobre el IVA (con el que se prevé una reducción de los costes de cumplimiento de las obligaciones

12 MONTIN, C. H., "La Smart Regulation nell'Unione Europea”. En F. BASILICA Y F. BARAZZONNI, Verso la Smart Regulation in Europa/Towards Smart Regulation in Europe, Maggioli Editori, 2013.

13 Entre ellas, el Real Decreto 1083/2009, de 3 de Julio, por el que se regula la memoria del análisis de impacto normativo y la Guía Metodológica para la elaboración de la Memoria del Análisis de Impacto Normativo aprobada por Acuerdo del Consejo de Ministros de 11 de Diciembre de 2009.

14 Así, la OCDE, en su Recomendación sobre política normativa y gobernanza de 2012, y en el Informe emitido en 2014 "Spain: From Administrative Reform to Continous Improvement", insiste en la idea de incluir la evaluación de impacto regulatorio en las etapas iniciales del proceso de diseño de políticas públicas y de formulación de propuestas normativas. 
empresariales de, al menos, un 55\%) o la puesta en marcha de un programa de simplificación de la política agraria común (con objeto de reducir sustancialmente los 250 Reglamentos existentes en la materia) ${ }^{\mathbf{1 5}}$.

En España, tras los cambios normativos producidos en estos últimos años y, en concreto, tras la entrada en vigor de la Ley 39/2015, de 1 de Octubre, del Procedimiento Administrativo Común de las Administraciones Públicas y de la Ley 40/2015, de 1 de Octubre, de Régimen Jurídico del Sector Público, que modifica "ad hoc" la Ley 50/1997, de 27 de Noviembre, del Gobierno, se hacía necesaria la aprobación de una nueva norma que adaptara las Memorias del Análisis del Impacto Normativo a la realidad jurídica actual.

El 14 de Noviembre de 2017 se publicó en el Boletín Oficial del Estado, el Real Decreto 931/2017, de 27 de Octubre, por el que se regula la Memoria del Análisis del Impacto Normativo, que deroga el anterior Real decreto 1083/2009, de 3 de Julio, con entrada en vigor a los 20 días de su publicación, esto es, el 14 de Diciembre de 2017.

Esta norma, que tiene por objeto desarrollar las previsiones contenidas en la Ley 50/1997, de 27 de Noviembre, del Gobierno, en lo que se refiere a la memoria del análisis del impacto normativo que debe acompañar a los anteproyectos de ley y proyectos de reales decretos-leyes, reales decretos legislativos y normas reglamentarias, se compone de tres artículos donde se estructura y se define el contenido de la memoria del análisis de impacto normativo, estableciéndose la posibilidad de una "Memoria Abreviada" cuando de la propuesta normativa no se deriven impactos apreciables o significativos.

Como regla general, la memoria del análisis del impacto normativo deberá contener una serie de consideraciones entre las que se encuentra la oportunidad de la propuesta de norma, que deberá incluir la identificación clara de los fines y objetivos perseguidos, la explicación de su adecuación a los principios de buena regulación recogidos en el artículo 129 de la Ley 39/2015 y, en especial, a los principios de necesidad, eficiencia y proporcionalidad ${ }^{\mathbf{1 6}}$, el análisis de las alternativas existentes y la justificación específica de la necesariedad de dicha norma en el caso de que no figure en el Plan Anual Normativo regulado en el artículo 25 de la Ley 50/1997².

15 COM (2016) 615 FINAL, Comunicación de la Comisión al Parlamento Europeo, al Consejo Europeo y al Consejo, de 14 de Septiembre de 2016. "Legislar mejor: obtener mejores resultados para una Unión más fuerte".

16 Respecto a este último, la norma determina que la iniciativa debe contener una regulación imprescindible para atender la necesidad a cubrir, tras constatar que no existen otras medidas menos restrictivas de derechos o que impongan menos obligaciones a los destinatarios.

17 Según este precepto, el Gobierno aprobará anualmente un Plan Normativo que contendrá las iniciativas legislativas o reglamentarias que vayan a ser elevadas para su aprobación en el año siguiente y que identificará, con arreglo a los criterios que se establezcan reglamentariamente, las normas que habrán 
También deberá contemplarse el contenido y análisis jurídico con las principales novedades introducidas, su engarce con el derecho nacional y de la Unión Europea, el listado pormenorizado de las normas a derogar, y la justificación, en caso de que se introduzcan trámites adicionales o distintos a los contemplados en la Ley 39/2015, atendiendo a la singularidad de la materia o de los fines perseguidos en la propuesta normativa. Asimismo, deberá hacerse referencia a su vigencia temporal, la entrada en vigor el rango normativo y, en su caso, la atribución directa de la potestad de desarrollo al titular de un departamento ministerial o a otros órganos dependientes o subordinados.

Otras dos consideraciones que deberán incluirse son las relativas al análisis sobre la adecuación de la propuesta de norma al orden de distribución de competencias, precisando el título o títulos competenciales en los que se basa la norma y el impacto económico y presupuestario, entendiendo el primero como la evaluación de las consecuencias de su aplicación sobre los sectores, colectivos o agentes afectados por la propuesta de norma, incluido el efecto sobre la competencia, la unidad de mercado, la competitividad, su encaje en la legislación vigente y su efecto sobre las pequeñas y medianas empresas. En cuanto al impacto presupuestario, éste deberá comprender, al menos, una referencia a los efectos en los ingresos y gastos públicos, incluyendo gastos de personal, dotaciones, retribuciones y cualesquiera otros gastos al servicio del sector público.

La Memoria deberá detectar y medir las cargas administrativas que conlleva la propuesta normativa (ya que, en aplicación del principio de eficiencia, debe evitarse aquellas cargas administrativas innecesarias), el impacto por razón de género, en la infancia, en la adolescencia y en la familia (esto es, el análisis y la valoración de los resultados que puedan seguirse de la aprobación del proyecto desde la perspectiva de la eliminación de desigualdades y de su contribución a la consecución de objetivos de igualdad de oportunidades y de trato, tanto respecto de las mujeres y hombres, como en la infancia, adolescencia y familia), así como cualquier otro extremo que pudiera ser relevante a criterio del órgano proponente y, en especial, a aquellos impactos de carácter social y medioambiental, de igualdad de oportunidades, de no discriminación y accesibilidad universal de las personas con discapacidad.

El análisis sobre coste-beneficio tendrá carácter potestativo si una norma específica o sectorial no lo exigiere, y resumirá todos los costes y beneficios de la norma,

de someterse a un análisis sobre los resultados de su aplicación, atendiendo fundamentalmente al coste que suponen para la Administración o los destinatarios y las cargas administrativas impuestas a estos últimos. Dicho Plan estará coordinado por el Ministerio de la Presidencia, con el objeto de asegurar la congruencia de todas las iniciativas que se tramiten y de evitar sucesivas modificaciones del régimen legal aplicable a un determinado sector o área de actividad en un corto espacio de tiempo. 
directos o indirectos, debiendo acreditarse que los beneficios esperados compensan o superan los costes derivados del proyecto y justifican la aprobación del mismo.

Otro epígrafe a incluir en la Memoria será la descripción de la tramitación y del período de consultas, que incluirá el resumen de las principales aportaciones recibidas en el trámite de consulta pública, la referencia a las consultas realizadas y observaciones recibidas en el trámite de audiencia e información pública así como su resultado y su reflejo en el texto del proyecto, los informes de las Comunidades Autónomas, Entidades Locales y otros informes o dictámenes preceptivos o facultativos evacuados durante la tramitación y, en el caso de tramitación urgente por Acuerdo del Consejo de Ministros, especial mención al mismo conforme a lo previsto en el artículo 27 de la Ley 50/97, de 27 de Noviembre.

Finalmente, la evaluación "ex post" deberá incluir la forma en la que se analizarán los resultados de la aplicación de las normas. Conforme a la normativa de aplicación, deberá indicarse la sistemática que se va a utilizar en la evaluación y la entidad u órgano que se considera idóneo para llevarlo a cabo.

Para la realización y estructuración de la Memoria del análisis de impacto normativo, el Real Decreto 931/2017, se remite a las indicaciones contenidas en la Guía Metodológica, referencias que, según lo dispuesto en su Disposición Adicional Primera, deberán entenderse, con carácter transitorio, a la Guía Metodológica para la elaboración de la memoria del análisis de impacto normativo aprobada por el Consejo de Ministros de 11 de Diciembre de 2009, mientras se produce la adaptación de dicha Guía a la nueva norma, que deberá elevarse al Consejo de Ministros en el plazo de seis meses desde la entrada en vigor del Real Decreto.

Por último, y como se ha comentado en párrafos anteriores, se prevé la posibilidad de una Memoria Abreviada (art. $3^{\circ}$ del Real Decreto 931/2017), cuando se estime que de la propuesta normativa no se derivan impactos apreciables o significativos. Esta memoria abreviada deberá incluir, al menos, la oportunidad de la norma, la identificación del título competencial prevalente, el listado de las normas que quedan derogadas, el impacto presupuestario y por razón de género, así como otros impactos detectados que se juzguen relevantes, la descripción de la tramitación y consultas realizadas y una descripción de la forma en la que se analizarán, en su caso, los resultados de la aplicación de la norma. 


\section{LA IMPORTANGIA DE UNA REGULAGIÓN INTELIGENTE PARA LA TRANSFORMACIÓN URBANÍSTICA DEL TERRITO- RIO: ESPEGIAL REFERENGIA A LA AUTONOMÍA LOGAL}

El importante desarrollo económico, acompañado del fuerte crecimiento demográfico y la actividad turística, junto con el crecimiento masivo y desordenado de las ciudades y municipios ha generado, en las últimas décadas, una ocupación excepcional del territorio, un proceso de ocupación del suelo y, como consecuencia, una degradación irreversible de compleja recuperación.

La extensión desmesurada y poco ordenada de la urbanización, el impacto de determinadas infraestructuras en el medio ambiente, el abandono de la agricultura, de la silvicultura y de la ganadería, la degradación de algunas áreas urbanas y la sobrefrecuentación de algunos parajes han contribuido a dichos procesos, que ponen en peligro los valores ambientales, culturales e históricos que el territorio ha adquirido durante años.

La importancia del Urbanismo y de la Ordenación del Territorio como elementos definitorios no sólo de ese territorio, sino de las políticas económicas, sociales, urbanísticas y otras de diversa índole a desarrollar, implica el respeto tanto de los valores naturales y/o urbanos existentes como del derecho de la población a un desarrollo sostenible de los mismos e, incluso, en el supuesto de territorios especialmente degradados, el derecho de los agentes administrativos, sociales y económicos integrantes del entorno, a intervenir en la mejora del mismo mediante fórmulas de participación conjunta.

La ordenación urbanística es asimilable a la noción de proyecto de territorio y debe comprender formas de transformación que tengan la capacidad de anticipar nuevas necesidades sociales mediante la consideración de las evoluciones en curso. Debería ser igualmente consecuente con el desarrollo sostenible y prever los procesos ecológicos y económicos a medio y largo plazo, así como aplicarse a la rehabilitación de espacios degradados (minas, canteras, vertederos, baldíos, etc.) para que puedan responder a los objetivos de calidad formulados. Y es en este momento previo, el de planificación y avance de los instrumentos urbanísticos y de ordenación del territorio, donde cobran especial importancia las memorias de análisis del impacto normativo y la definición de los instrumentos de participación ciudadana y de colaboración con los agentes sociales y económicos como herramientas para evaluar la efectiva incidencia del modelo de ciudad o territorio elegido en el desarrollo económico del mismo.

No existe, por tanto, una estrategia única de desarrollo urbanístico local, supralocal o regional, tal vez porque la esencia de lo local es la diferencia: cada región 
se distingue de otras por su paisaje, la naturaleza de sus recursos naturales, por el nivel de sus infraestructuras y equipamientos, por la calidad de sus comunicaciones, por el nivel de instrucción de sus habitantes, por las expectativas de renta y de bienestar que éstos tienen, por el grado y consolidación de su organización política (entendida a nivel de participación de agentes sociales y económicos), por su sistema de creencias y actitudes y, en resumen, por el grado de eficacia en captación de recursos y en administración de los mismos.

Jane Jacobs ${ }^{18}$, en su estudio sobre el desarrollo de las grandes ciudades y la evolución de sus economías, pone de manifiesto que, por debajo del entramado nacional, organizado por el Estado, las ciudades seguían teniendo, y sobre todo, podían tener, una vida económica propia, unas capacidades productivas y, en suma, que podían planificar su propio desarrollo económico como "órganos económicos primarios".

Propone para ello dos mecanismos básicos: el primero es la producción de bienes, mercancías o servicios exportables; como efecto inducido del éxito en ese primer proceso aparece el concepto más importante: la sustitución de importaciones. Sin aumento de la producción de la demanda de bienes y servicios, es decir, sin inversiones productivas que fomenten ese incremento, no hay empleo sino subsidiación.

Dicho empleo no se genera únicamente con políticas activas de empleo, sino que las mismas deben encuadrarse dentro de la política económica y de desarrollo urbanístico y territorial de cada región. Ejemplo de ello son las experiencias implementadas a nivel local o regional en distintos territorios con un bajo nivel de desarrollo que han confirmado que aquellas regiones que habían invertido en formación y calidad de vida (mediante actuaciones en materia de vivienda, medio ambiente y comunicaciones e infraestructuras básicas) han tenido un cierto despegue mientras que aquellas que han mantenido los esquemas clásicos de subvención directa a fondo perdido han seguido estancadas.

Si bien las directrices estatales y autonómicas son esenciales a la hora de planificar el desarrollo urbanístico de una región, hay que valorar también las competencias asignadas a los entes locales ya que el desarrollo económico y urbanístico de un territorio depende, en gran medida, de la planificación y capacidad técnica de los agentes locales y/o supralocales implicados, elementos claves para la movilización de los recursos.

Al respecto, y conforme a jurisprudencia reiterada, la autonomía local no puede ver limitada su virtualidad al reconocimiento de un mero derecho a la participación de las entidades locales en el ejercicio de competencias ajenas, tomando parte

18 JACOBS, J., The Economy of Cities, trad. cast. La economía de las ciudades, Edición 62, 1969. 
consiguientemente en la adopción de las decisiones que corresponda a otros sujetos mediante su intervención en el procedimiento previsto en cada caso.

Desde luego, esta dimensión del principio de la autonomía local goza de la protección constitucional y tiene su amparo en la normativa estatal básica (artículo 2 de la Ley 7/1985, de 2 de Abril, de Bases del Régimen Local). Pero no menos evidente es que la autonomía local no puede ver reducida su alcance a esta sola dimensión participativa y ha de proyectarse asimismo en la esfera material sobre su propio haz de competencias; entre otras razones, a fin de satisfacer las exigencias igualmente dimanantes de la Carta Europea de la Autonomía Local de 1985, cuyo artículo 3 establece que "por autonomía local se entiende el derecho y la capacidad efectiva de las entidades locales de ordenar y gestionar una parte importante de los asuntos públicos, en el marco de la ley, bajo su propia responsabilidad y en beneficio de sus habitantes".

Sin embargo, conforme a lo indicado por la STS 543/2016, de 12 de Febrero, entre otras, lo que no les está asegurado a las corporaciones locales es un contenido concreto ni un determinado ámbito competencial (STC 40/1998), sino que la concreción de las competencias de las corporaciones locales habrá de realizarse por medio de las leyes correspondientes, atendiendo a los principios asimismo fijados por la normativa estatal básica ${ }^{19}$.

Tampoco existe, pues, la garantía de la asignación concreta de un "quantum" de competencias y éstas habrán de determinarse en cada sector del ordenamiento jurídico con base en el respectivo grado de los intereses autonómicos y locales confluyentes en cada caso.

En el supuesto que nos ocupa, esto es, la ordenación territorial y urbanística, resulta innegable que la esfera competencial de la entidad local resulta afectada y condicionada, pero también lo es que dicha entidad está asimismo en grado de seguir ejerciendo sus competencias sobre clasificación urbanística del suelo.

La autonomía local reconocida en los artículos 137, 140 y 141 de la Constitución Española de 1978, que se configura como una garantía institucional con un contenido mínimo que el legislador debe respetar y que se concreta, básicamente, en el derecho de la comunidad local a participar a través de órganos propios en el

19 Artículo 2 LRBRL: "Para la efectividad de la autonomía garantizada constitucionalmente a las Entidades Locales, la legislación del Estado y la de las Comunidades Autónomas, reguladora de los distintos sectores de acción pública, según la distribución constitucional de competencias, deberá asegurar a los Municipios, las Provincias y las Islas su derecho a intervenir en cuantos asuntos afecten directamente al círculo de sus intereses, atribuyéndoles las competencias que proceda en atención a las características de la actividad pública de que se trate y a la capacidad de gestión de la Entidad Local, de conformidad con los principios de descentralización, proximidad, eficacia y eficiencia, y con estricta sujeción a la normativa de estabilidad presupuestaria y sostenibilidad financiera". 
gobierno y administración de cuantos asuntos le atañen, graduándose la intensidad de esta participación en función de la relación existente entre los intereses locales y supralocales dentro de tales asuntos o materias, según el Tribunal Constitucional ha recordado recientemente en su STC 132/2014, con cita, entre otras, de la STG 240/2006 (también en la STG 57/2015, de 18 de marzo).

En las reiteradas palabras del Tribunal Constitucional, la garantía institucional de la autonomía local no asegura un contenido concreto ni un determinado ámbito competencial, "sino la preservación de una institución en términos reconocibles para la imagen que de la misma tiene la conciencia social en cada tiempo y lugar, de suerte que solamente podrá reputarse desconocida dicha garantía cuando la institución es limitada, de tal modo que se le priva prácticamente de sus posibilidades de existencia real como institución para convertirse en un simple nombre" ( STC 32/1981).

Es por ello que, a través de las administraciones locales, y dentro del proceso de planificación urbanística, pueden y deben llevarse a cabo acciones de captación de recursos económicos y de obtención de programas de desarrollo económico local, ya sea a través de la concertación con otras instituciones territoriales, o mediante la incentivación de un tejido asociativo local que fomente tanto la participación en el diseño y redacción del modelo de ciudad como la creación de "microempresas" relacionadas con las fortalezas existentes a nivel local, generando el llamado "efecto demostrativo" que sirva de germen para otros potenciales emprendedores.

Pero no hay que olvidar que el desarrollo del territorio no sólo depende de factores económicos o de inversiones. Es en el momento inicial de esta planificación cuando más importancia hay que dar determinados elementos que van a propiciar que el desarrollo urbanístico de ese territorio sea diferente y, por tanto, único, con respecto a otros semejantes.

Es aquí donde la gestión urbanística cobra especial importancia entendida como aquellas acciones encaminadas a garantizar el mantenimiento regular del entorno desde una perspectiva de desarrollo sostenible, con el fin de guiar y armonizar las transformaciones inducidas por los procesos sociales, económicos y medioambientales.

Destacables en este aspecto son los Informes o Memorias de Sostenibilidad Económica recogidos en el artículo 22 del Real Decreto Legislativo 7/2015, de 30 de Octubre, por el que se aprueba el Texto refundido de la Ley de Suelo y Rehabilitación Urbana, y que determina que, con carácter preceptivo, cualquier instrumento de ordenación que implique actuaciones de transformación urbanística deberá incluir dicho informe o memoria, con expresa ponderación del impacto de la actuación en las Haciendas Públicas afectadas, el coste del mantenimiento de las infraestructuras necesarias o de la puesta en marcha y la prestación de los servicios resultantes, así como la suficiencia y adecuación del suelo destinado a usos productivos. 
Dicha obligatoriedad de emisión del Informe o Memoria de Sostenibilidad Económica se amplía a cualquier instrumento de ordenación y ejecución de actuaciones en el medio urbano, con independencia de que supongan o no transformación urbanística, en términos de rentabilidad, de adecuación a los límites del deber legal de conservación y de un adecuado equilibrio entre los beneficios y cargas derivados de la misma, para los propietarios incluidos en su ámbito de actuación, y su importancia es tal que su ausencia o escasa justificación puede determinar la nulidad del instrumento donde aparezca recogido.

Así, la interpretación que del antiguo artículo 15.4 del texto Refundido de la Ley de Suelo de 2008 (actual artículo 22.4 del Real Decreto Legislativo 7/2015, de 30 de Octubre, por el que se aprueba el Texto refundido de la Ley de Suelo y Rehabilitación Urbana) hace el Tribunal Supremo implica la diferenciación entre los conceptos de sostenibilidad económica y de viabilidad económica (ligada al estudio económico-financiero que prevé el coste de ejecución de la actuación y las fuentes de financiación).

El análisis de la sostenibilidad económica tiene que justificar la sostenibilidad de la actuación para las arcas públicas desde que se inicia hasta que se termina la responsabilidad para la Administración de las nuevas infraestructuras y servicios necesarios, sin que pueda entenderse subsumido en el estudio económico financiero del Plan porque persiguen finalidad distinta y su ausencia puede provocar la nulidad de un Plan General de Ordenación urbanística (STS de 30 de Marzo de 2015, rec. 1587/2013).

Por ello y con carácter previo a dicho análisis, también es necesario asumir una serie de actuaciones previas y/o paralelas a la ordenación urbanística y económica del territorio que no sólo garanticen la viabilidad y sostenibilidad de la actuación a desarrollar sino, también, la implicación y participación del ciudadano en los pasos previos a la formulación de instrumentos de ordenación territorial y urbanística.

Es esencial reforzar los valores de identidad y pertenencia territorial, fomentando el espíritu de vecindad y el componente de la convivencia, pues sólo de esa forma se promueve una imagen del municipio o territorio y un sentimiento en la población encaminado a su potenciación. Es difícil poner en marcha un proyecto de desarrollo urbanístico y económico si partimos de una minusvaloración de los recursos y potencialidades locales por los propios habitantes.

Mejorar la calidad ambiental y las condiciones de vida, valorando el medio ambiente, la rehabilitación, la consolidación urbana, y el patrimonio edificado, reforzando la vida cultural y científica y promoviendo la solidaridad y la integración social debe ser un antecedente que inspire la formulación de cualquier instrumento de desarrollo territorial, así como promover la intensificación de los procesos de re- 
lación e integración en espacios más amplios, fundamental para potenciar las capacidades exportadoras de la economía local.

En resumen, para que el desarrollo urbanístico de un territorio pueda considerarse efectivo, es necesaria la mejora global en el bienestar económico y social de los residentes y del medio físico donde residen. Los profundos cambios demográficos, económicos y sociales experimentados en las últimas décadas hace que el desarrollo del territorio deba plantearse como una vuelta a aquellos recursos ociosos o infrautilizados, recuperando aquellas actividades productivas que fueron abandonadas y que hoy pueden volver a ser fuente de riqueza, pero también creando otras nuevas que permitan el aprovechamiento y la optimización de nuevas ideas y oportunidades. En definitiva, una acción de movilización de factores en el contexto local.

Finalizado el ciclo inmobiliario de los últimos años, basado fundamentalmente en el crecimiento urbanístico expansionista y, en ocasiones, descontrolado, se hace necesario poner en marcha procesos de intervención urbanística que introduzcan en la comunidad una estrategia de cambio cultural y una perspectiva de crecimiento que empuje a los individuos a actuar para aprovechar las oportunidades presentes en el medio.

Esta estrategia debe basarse en la detección de lo que se denomina "vacíos productivos", esto es, aquellos espacios para la producción de objetos o servicios demandados o demandables por la sociedad local que, o no son satisfechos por el aparato productivo local o, simplemente, todavía no han sido implementados en el mercado así como en la acción de las entidades locales en dos vertientes: De un lado, la facilitadora o catalizadora de la dinámica económica del territorio, de tal forma que de salida a las capacidades endógenas de desarrollo económico y urbanístico y, de otro, la generadora de iniciativas en su propio área de actuación, apoyando la gestión empresarial e interviniendo en el desarrollo y dirección de las iniciativas que surjan.

\section{EL PRINCIPIO DE "SMART REGULATION" EN LA ORDENA- GIÓN URBANÍSTICA Y TERRITORIAL}

La acción local para la inclusión del Principio de "Smart Regulation" en el desarrollo urbanístico y económico de un territorio y para el diseño de políticas sostenibles que incentiven la conservación e, incluso, la mejora de los espacios urbanos y rurales, debe plantearse desde las siguientes consideraciones:

\section{La dimensión local}

El ámbito local es el nivel más cercano al ciudadano y permite detectar las necesidades locales insatisfechas y organizar y diseñar el modelo de ciudad que mejor 
se adapte al entorno. Lejos de ser únicamente el lugar donde se ponen en práctica decisiones adoptadas en otros niveles, en él también se pueden combinar diferentes instrumentos y desarrollar formas de dar valor añadido a las decisiones tomadas por otras administraciones. El ámbito local no está limitado por fronteras administrativas, sino que, con mayor frecuencia, el territorio apropiado para la intervención local viene definido por las afinidades culturales con que se identifican los ciudadanos del lugar, por los sistemas productivos y los flujos comerciales locales.

Como afirma Gutiérrez Colomina ${ }^{20}$, el Urbanismo no puede seguir siendo el soporte financiero del Presupuesto municipal, siendo necesario un enfoque estratégico y eficiente de los bienes de dominio público y patrimonial que permitan la reducción de costes y la optimización de los recursos municipales.

Ya hemos indicado anteriormente que, de conformidad con lo dispuesto en el artículo 2 de la Ley 7/85, de 2 de Abril, reguladora de las Bases del Régimen Local, la distribución de competencias debe asegurar a los municipios su derecho a intervenir en cuantos asuntos afecten al círculo de sus intereses con base en los principios de descentralización, proximidad, eficacia y eficiencia, con las limitaciones fijadas en la normativa sobre estabilidad presupuestaria y sostenibilidad financiera. No obstante, la concreción de dichas competencias vendrá determinada por las leyes correspondientes (STS 543/2016 y STG 40/1998, entre otras) por lo que es absolutamente imprescindible afianzar y coordinar la distribución competencial en aquellas materias que incidan directamente en el desarrollo urbanístico de un municipio.

\section{El enfoque integrado}

Todas las políticas desarrolladas en el ámbito local deben integrarse en una estrategia única a fin de maximizar su eficiencia. A este respecto, cualquier planificación urbanística debe considerarse una extensión de otros instrumentos de la política de desarrollo tales como la planificación económica, la medio ambiental o la social.

Asî, la STC 61/1997, de 20 de Marzo (FJ 6.b) segundo párrafo indica que "la competencia autonómica exclusiva sobre urbanismo ha de integrarse sistemáticamente con aquellas otras estatales que, si bien en modo alguno podrían legitimar una regulación general del entero régimen jurídico del suelo, pueden propiciar, sin embargo, que se afecte puntualmente a la materia urbanística" mediante el establecimiento de las condiciones básicas que garanticen la igualdad en el ejercicio del derecho de propiedad urbana, determinados aspectos de la expropiación forzosa o de la responsabilidad administrativa.

20 VVAA, Reforma del Régimen Local: La Ley de Racionalización y Sostenibilidad de la Administración Local: veintitrés Estudios, Editorial Aranzadi, 2014. 
No hay que olvidar en este apartado, el alcance constitucional otorgado al principio de cooperación por la Jurisprudencia (STS 4743/2017, de 27 de Diciembre). Dicho principio, "que no es menester justificar en preceptos concretos, se encuentra implícito en la propia esencia de la forma de organización territorial del Estado que se implanta en la Constitución” (STG 18/1982, de 4 de mayo , FJ 14), pues entronca con "la necesidad de hacer compatibles los principios de unidad y autonomía" (STG 214/1989, FJ 20 e).

En cuanto a su caracterización, conviene, como primer paso, distinguir el principio de cooperación de la coordinación. En este sentido, la doctrina jurisprudencial conecta la cooperación con la idea de la voluntariedad y la coordinación con la de la imposición. Así, "la voluntariedad en el caso de la cooperación frente a la imposición en la coordinación es, por sí mismo, un elemento diferenciador de primer orden, lo que explica y justifica que, desde la perspectiva competencial distintas hayan de ser las posibilidades de poner en práctica unas y otras fórmulas" (STC 214/1989, de 21 de diciembre, FJ 20 f).

El segundo criterio a tener en cuenta para caracterizar a la cooperación es que su instrumentación y puesta en práctica no permite alterar las competencias de los sujetos llamados a cooperar. Así, la Jurisprudencia se ha manifestado en reiteradas ocasiones respecto de la necesidad de fomentar "la cooperación entre las Administraciones públicas implicadas mediante la búsqueda o creación de instrumentos que permitan articular su actuación, aunque sin alterar la titularidad y el ejercicio de las competencias propias de los entes en relación" (SSTC 77/1984 , FJ 3 ; 76/1983 , FJ 13 ; 227/1988, FJ 20 ; y 214/1989 , FJ 20, 118/1998, de 4 de junio , FJ 12).

En cuanto a las técnicas propias del principio de cooperación, "por lo general no prejuzga cuál debe ser la correcta técnica a través de cuya mediación dicha coparticipación se articule" (STC 68/1996 , FJ 10), si bien se ha entendido que el mismo puede satisfacerse generalmente, ya dando entrada a representantes o comisionados de las Comunidades Autónomas en los órganos del Estado, ya integrando a las Comunidades Autónomas en el curso de los procedimientos públicos que ejecuten la legislación estatal (STC 146/1992 ,FJ 4). Así pues, el Tribunal Constitucional ha venido reconociendo un margen de discrecionalidad en la determinación de los específicos mecanismos cooperativos, lo que no implica que dicho margen se conciba como un espacio totalmente inmune al control jurisdiccional, pues la, en principio, amplia esfera de libertad aludida puede eventualmente comprimirse en función de la relevancia del ámbito de la política autonómica concernido en cada caso (STC 68/1996, FJ 10 o STG 118/1998, de 4 de junio , FJ 12).

En todo caso, conviene resaltar que la doctrina constitucional recaída sobre los diversos instrumentos de cooperación ha reiterado el criterio aludido de que su pues- 
ta en práctica no permite alterar las competencias propias de las Administraciones actuantes. Así, respecto de los convenios de cooperación (STC 13/1992, de 6 de febrero, FFJJ 7 y 10, con cita de la STG 95/1986, de 10 de julio, FJ 5), las conferencias sectoriales (STC 76/1983, de 5 de agosto, FJ 13) o los Reales Decretos de traspasos (STG 11/1986, de 28 de enero, FJ 3), entre otras figuras.

\section{La participación ciudadana}

Tras el profundo cambio cultural que ha experimentado el enfoque de las cuestiones relacionadas con el urbanismo y el medio ambiente, las políticas de ordenación territorial no deben considerarse una preocupación exclusiva de los responsables políticos y de los agentes económicos, sino algo que afecta al conjunto de la ciudadanía, lo que hace necesario mejorar la coordinación existente entre los agentes locales y los distintos niveles institucionales. La creación de un tejido asociativo que reúna la fuerza de uno o varios colectivos es una condición esencial para el éxito de la estrategia de un desarrollo urbanístico sostenible.

No hay que olvidar en este sentido lo dispuesto en el artículo 5 del Real Decreto Legislativo 7/2015, de 30 de Octubre, por el que se aprueba el Texto Refundido de la Ley de Suelo y Rehabilitación Urbana, cuando establece con carácter general los derechos de los ciudadanos en el ámbito urbanístico y de ordenación del territorio, destacando, entre otros, la participación efectiva en los procedimientos de elaboración y aprobación de cualesquiera instrumentos de ordenación del territorio o de ordenación y ejecución urbanísticas y de su evaluación ambiental mediante la formulación de alegaciones, observaciones, propuestas, reclamaciones y quejas y el derecho a obtener de la Administración una respuesta motivada, conforme a la legislación reguladora del régimen jurídico de dicha Administración y del procedimiento de que se trate.

La STS 3587/2015, de 22 de Julio, indica que "se trata de un derecho que, como hemos señalado, se incardina en la llamada democracia urbanística y que pretende lograr una mayor legitimidad democrática al Plan" (en ese caso, se refiere al Plan Territorial Especial Supramunicipal Área de Tratamiento Centralizado de Residuos de Asturias). Sin dudar de la legitimidad democrática de los órganos, representativos o no, encargados legalmente de la planificación territorial y urbanística, la sentencia indica que el legislador pretende dar efectividad al principio de participación, recogido con carácter general en el artículo 105 de la Constitución, otorgando un plus de legitimidad a algunos aspectos de la acción administrativa sectorial tan importantes y con tanta incidencia en el entorno físico y ambiental y sobre todo en su calidad, afectando en definitiva a la vida habitual de los ciudadanos. 


\section{El enfoque ascendente}

El desarrollo urbanístico de un territorio ha de estar basado en un análisis de las necesidades y las cualificaciones locales a fin de generar las soluciones apropiadas, ya que no existen soluciones únicas que permitan implementar un modelo de ciudad concreto en distintos territorios.

Cada territorio posee unas características diferenciadas que provocan que el modelo de ciudad que se pretenda aplicar por haber resultado exitoso en otros casos, pueda llegar a fracasar por no tenerse en cuenta los elementos o circunstancias existentes. Esto debería impulsar a los entes locales a analizar previamente su modelo de actuación urbanística a fin de satisfacer de manera óptima las necesidades locales.

El Real Decreto Legislativo 7/2015, de 30 de Octubre, por el que se aprueba el Texto Refundido de la Ley de Suelo y Rehabilitación Urbana, recoge, en su artículo tercero, la regulación del Principio de Desarrollo Territorial y Urbano Sostenible, según el cual, las políticas públicas relativas a la regulación, ordenación, ocupación, transformación y uso del suelo deben propiciar el uso racional de los recursos naturales armonizando los requerimientos de la economía, el empleo, la cohesion social, la igualdad de trato y de oportunidades, la salud y la seguridad de las personas y la protección del medio ambiente.

Son continuas las referencias a dicho principio en la Jurisprudencia de la última década. Así, las SSTS 5189/2012 y 5191/2012, de 5 de Julio (rec. 3869/2010 y 4066/2010) se remiten a este Principio de Desarrollo Territorial y Urbano Sostenible recogido en el antiguo artículo 2 del Texto Refundido de la Ley de Suelo, indicando que el mismo comporta el uso racional de los recursos naturales y, entre otros aspectos, "la protección, adecuada a su carácter, del medio rural y la preservación de los valores del suelo innecesario o inidóneo para atender las necesidades de transformación urbanística" (apartado 2.b del antiguo TRLS08).

\section{El entorno propicio}

El desarrollo de estrategias locales integradas en materia de urbanismo depende, en gran medida, de la normativa regional, estatal e, incluso, comunitaria, no sólo en referencia a las posibles competencias concurrentes de distintos niveles institucionales sino también a las políticas fiscales existentes que pudieran facilitar la iniciativa local.

Dada la dimensión y el papel que toman las distintas administraciones en el diseño del territorio y en las políticas urbanísticas, es aconsejable evitar las confrontaciones y los conflictos competenciales que pueden llevar al fracaso del modelo de ciudad propuesto. En este aspecto, conviene hacer referencia a lo dispuesto en el artí- 
culo 4.1 del citado Real Decreto Legislativo 7/2015, de 30 de Octubre, por el que se aprueba el Texto Refundido de la Ley de Suelo y Rehabilitación Urbana, por cuanto "el ejercicio de la potestad de ordenación territorial y urbanística debe ser motivado, con expresión de los intereses generales a los que sirve".

La ordenación territorial y urbanística es una función pública que persigue dar una respuesta homogénea a los múltiples problemas que suscita la utilización del medio físico, y que, por tanto, no puede emanar únicamente de uno solo de los tres niveles de Administraciones públicas territoriales (estatal, autonómica y local). Todas ellas ostentan títulos competenciales que repercuten en esa ordenación. Precisamente porque la toma de decisiones sobre la ordenación territorial se genera a la vez en diferentes niveles territoriales es inevitable que se produzca un entrecruzamiento de competencias que es preciso armonizar, y de ahí surge la necesidad de integrar esas competencias sectoriales en una unidad provista de sentido. Aun cuando es cierto que todas las Comunidades autónomas han asumido la competencia exclusiva sobre la ordenación del territorio y el urbanismo (ex art. 148.1.3 de la Constitución), no es menos cierto que el Estado mantiene competencias que repercuten sobre esa ordenación, competencias generales cuyo ejercicio incide sobre todo el territorio español, condicionando así las decisiones que sobre la ordenación del territorio y del urbanismo pueden adoptar las Comunidades Autónomas: potestad de planificación de la actividad económica general del art. 131.1 de la Constitución o la titularidad del dominio público estatal del art. 132.2 de la misma, y competencias sectoriales atribuidas al Estado ex art. 149.1 de la propia Constitución, cuyo ejercicio puede condicionar legítimamente la competencia autonómica.

$\mathrm{Al}$ determinarse cuál es la competencia prevalente, la jurisprudencia ha resaltado una y otra vez que "la competencia autonómica en materia de urbanismo y ordenación del territorio no puede entenderse en términos tan absolutos que elimine o destruya las competencias que la propia Constitución reserva al Estado, aunque el uso que éste haga de ellas condicione necesariamente la ordenación del territorio, ya que el Estado no puede verse privado del ejercicio de sus competencias exclusivas por la existencia de una competencia, aunque sea también exclusiva, de una Comunidad Autónoma, pues ello equivaldría a la negación de la misma competencia que asigna la Constitución a aquél” (STS 9 de Marzo de 2011, rec 3037/2008).

\section{La integración de la práctica administrativa}

A pesar de que las políticas públicas se organizan cada vez con más frecuencia con arreglo a objetivos multisectoriales, todavía se gestionan, principalmente, en el marco de programas sectoriales. Las prácticas administrativas actuales fomentan la especialización de tareas en detrimentos de planteamientos globales, lo que se debe a la segmentación de las competencias de decisión y de gestión entre los departamen- 
tos a todos los niveles, de manera que cada departamento da prioridad a sus propios ámbitos.

En la medida en que las estrategias integradas de desarrollo urbanístico precisan de planteamientos multisectoriales, esta segmentación de las prácticas administrativas tiene a obstaculizar su diseño y aplicación.

En palabras del Profesor Gutiérrez Colomina ${ }^{21}$, "el desarrollo invertido y poco sistemático del proceso legislativo" y "la gran cantidad de conceptos jurídicos indeterminados incorporados a la legislación urbanística" han provocado la declaración de nulidad de numerosos instrumentos urbanísticos por los tribunales con los consecuentes efectos tan negativos que estas sentencias han producido en la actividad socioeconómica.

Fue el Tribunal Constitucional, en su STC 194/2004, de 10 de noviembre, el que estableció los cánones constitucionales de coordinación y cooperación entre las diversas Administraciones, al pronunciarse sobre la gestión de los Parques Nacionales, señalando al respecto:

"Acerca de las potestades de coordinación de que el Estado dispone y que pudieran fundamentar el sistema de cogestión controvertido, hay que partir, para fijar su alcance, de la noción y sentido propios de la función coordinadora".

La STG 32/1983 determinó ya el significado de la coordinación, precisando que la misma "persigue la integración de la diversidad de las partes o subsistemas en el conjunto o sistema, evitando contradicciones y reduciendo disfunciones que, de subsistir, impedirían o dificultarían la realidad misma del sistema" (STC 32/1983, de 28 de abril, FJ 2).

La misma Sentencia incide en la competencia estatal de coordinación general, señalando al respecto que, aunque constituye un reforzamiento o complemento de la noción de bases, es una competencia distinta a la fijación de bases y que la competencia de coordinación general presupone lógicamente que hay algo que debe ser coordinado, esto es, presupone la existencia de competencias de las Comunidades Autónomas, competencias que el Estado, al coordinarlas, debe obviamente respetar.

La competencia estatal de coordinación general significa no sólo que hay que coordinar las partes o subsistemas sino que esa coordinación general le corresponde hacerla al Estado y, en consecuencia, la coordinación general debe ser entendida como la fijación de medios y de sistemas de relación que hagan posible la información recíproca, la homogeneidad técnica en determinados aspectos y la acción

21 "Estudio jurisprudencial sobre los efectos de la nulidad del planeamiento de ordenación del territorio y urbanístico de Andalucía”, en Territorio y Urbanismo, 2017, CIVISUR. 
conjunta de las autoridades estatales y comunitarias en el ejercicio de sus respectivas competencias de tal modo que se logre la integración de actos parciales en la globalidad del sistema (STC 32/1983, FJ 2).

Como complemento de la noción general de coordinación que se acaba de exponer, el Tribunal Constitucional hace hincapié en tres ideas. La primera de ellas es que la coordinación es una facultad que guarda estrecha conexión con las competencias normativas, de modo que el titular de estas últimas ostenta aquella facultad como complemento inherente (STG 104/1988, de 8 de junio), es decir, "no puede reducirse ni confundirse las manifestaciones específicas de coordinación que aparecen en nuestra Constitución (art. 149.1, 13, 15, 16, etc.) como competencia adicional a una competencia normativa limitada, con las funciones generales de coordinación que corresponden al Estado cuando sus competencias normativas son plenas, dado que aquél no puede desentenderse en absoluto de la ejecución autonómica de la legislación estatal. Resultan así posibles formas de intervención normativa que establezcan reglas que cumplan una función coordinadora de las Administraciones Autonómicas entre sí y con el Estado" (STC 104/1988, de 8 de junio, FJ 2).

La segunda idea es que la coordinación "conlleva un cierto poder de dirección. Consecuencia de la posición de superioridad en que se encuentra el que coordina respecto al coordinado" (STC 214/1989, de 21 de diciembre, FJ 20 f).

Por último, hay que destacar, por su relevancia, que la facultad de coordinación no otorga a su titular competencias que no ostente y, en concreto, facultades de gestión complementarias. En la señalada STC 32/1983 se indicaba que la coordinación se materializa en la fijación de medios y sistemas de relación entre distintas autoridades para propiciar el ejercicio de "sus respectivas competencias", de manera que "tal coordinación no supone, sin embargo una sustracción o menoscabo de las competencias de las entidades sometidas a la misma" (STC 27/1987, de 27 de febrero, FJ 2). En definitiva, "ni la competencia en materia de coordinación ni la competencia sobre las bases de la planificación autorizan al Estado para atraer hacia su órbita de actividad cualquier competencia de las Comunidades Autónomas por el mero hecho de que su ejercicio pueda incidir en el desarrollo de las competencias estatales sobre determinadas materias. La coordinación no supone una sustracción o menoscabo de las competencias de las entidades sometidas a la misma: antes bien, presupone lógicamente la titularidad de las competencias en favor de la entidad coordinada (STC 27/1987), por lo que no puede servir de instrumento para asumir competencias autonómicas, ni siquiera respecto de una parte del objeto material sobre el que recaen" (STC 227/1988, de 29 de noviembre, FJ 20 e). 


\section{La Financiación adaptada a las necesidades locales}

Las microempresas y las iniciativas locales de desarrollo económico han de superar trabas considerables para obtener financiación, en gran parte a causa de la dificultad en la presentación de garantías materiales.

En general, cuando existe financiación pública, la misma está vinculada a condiciones específicas exigidas por la política de competencia y de auditoría pública, que pueden dificultar el acceso a los fondos, sobre todo en el caso de microempresas y emprendedores individuales.

Existen, además, otras fuentes de financiación todavía infrautilizadas que merecen especial atención, entre las que cabe citar el microcrédito, el capital de inversión local (especialmente con finalidad social), los recursos de las fundaciones y determinadas formas de financiación alternativas como las Cajas de ahorro local solidario o las más recientes iniciativas de "crowdfunding".

Entre las distintas opciones existentes, y asumido que el Urbanismo no puede seguir siendo el soporte financiero del Presupuesto municipal, el Profesor Gutiérrez Colomina ${ }^{22}$ propone un enfoque estratégico y eficiente de los bienes de dominio público y patrimoniales, mediante una planificación más eficiente de la gestión de los bienes públicos y especialmente de los municipales. Así, expone que "no hay que perder de vista, que el estudio y la planificación de los bienes, no puede limitarse a los bienes patrimoniales, sino incluir también los demaniales". Esta inclusión no obedece sólo a que los bienes demaniales puedan ser desafectados, incluso con carácter parcial (pensando, por ejemplo, en la desafectación del vuelo o del subsuelo a la que ha dado carta de legitimidad el art. 17.4 del TRLS08), sino porque la legislación patrimonial otorga al concesionario demanial los mismos derechos que al propietario sobre las edificaciones, mientras dure la concesión y le da, por ello, la posibilidad de constituir derechos reales durante el mismo plazo sobre las edificaciones construidas. Hay una serie de posibilidades derivadas de una buena gestión estratégica de los bienes patrimoniales y demaniales, que servirían para poder reducir costes en la instalación de los servicios municipales, para llevar a cabo aparcamientos en el subsuelo sin contar con recursos dinerarios o para la construcción en dotaciones o equipamientos municipales, viviendas sociales, etc.

22 "La incidencia de La Ley 27/2013, de 27 de Diciembre de Racionalización y Sostenibilidad de la Administración Local en el Régimen Jurídico de las Grandes Ciudades", en VVAA, Reforma del Régimen Local: La Ley de Racionalización y Sostenibilidad de la Administración Local: veintitrés Estudios, Editorial Aranzadi, 2014. 


\section{Estructuras intermedias de apoyo}

Normalmente, las actividades locales de fomento del desarrollo económico no surgen espontáneamente. La existencia de estructuras intermedias de apoyo (agencias, observatorios, universidades...) es con frecuencia la clave del éxito de las iniciativas locales. Así pues, la colaboración y el apoyo concedido por parte de la administración local o regional a estas estructuras y organizaciones puede resultar esencial.

En este apartado hay que hacer referencia a las denominadas Entidades del Tercer Sector, esto es, entidades que surgen "como complemento a los dos tradicionales sectores, sector Público y Sector Privado, y se integra por aquellas entidades que no son públicas, sino privadas, pero carecen de ánimo de lucro y, además, realizan actividades de interés general. Son lo que se conoce como organizaciones no gubernamentales o la sociedad civil, como expresión social de una solidaridad organizada" (STS de 21 de Mayo de 2015, rec. 499/2013).

\section{Sistemas apropiados de formación y concienciación a la población local}

Los sistemas de formación profesional suelen adaptarse con gran dificultad a los cambios que pueden producirse a nivel local o regional. Cada vez es más frecuente que los individuos pertenezcan simultáneamente a distintas categorías (como es el caso de los desempleados que aspiran a crear su propia empresa), de manera que es necesario proporcionar una formación que se ajuste a las necesidades específicas de cada uno, y donde debe estudiarse en profundidad la inclusión del modelo de ciudad elegido a los efectos de facilitar la adecuada conexión entre el potencial emprendedor y las políticas territoriales y urbanísticas que se pretenden implantar.

Por otro lado, las nuevas ocupaciones que aprovechan las nuevas posibilidades profesionales pueden exigir habilidades especiales (formación pluridisciplinar, habilidades sociales, capacidad de iniciativa, etc.) o estructuras de acceso (teletrabajo). La formación profesional debe cumplir su propósito en todas estas circunstancias.

En este sentido, a nivel nacional existe un Catálogo de Especialidades Formativas que incluye 26 familias profesionales y que se regula por el Real Decreto 395/2007, de 23 de Marzo, por el que se regula el subsistema de formación profesional para el empleo, si bien las comunidades autónomas se encuentran habilitadas para su ampliación si existieran nuevas especialidades formativas con significado relevante para el empleo dentro de su territorio. 


\section{Políticas económicas, estructurales y sociales que se refuercen mutuamente}

La aplicación del principios de "Smart Regulation" en la ordenación urbanística y del modelo de ciudad de un territorio exige aplicar estrategias y políticas económicas, estructurales y sociales que se refuercen mutuamente. Si bien es cierto que todas contribuyen, es frecuente que cada una de ellas se aborde con enfoques o perspectivas distintas.

Independientemente del organismo público que haya asumido la coordinación o implementación de la estrategia, se recomienda una concertación entre los diferentes niveles de la administración del territorio (concertación vertical) y entre distintos organismos y entes sectoriales del mismo nivel (concertación horizontal).

La ordenación del territorio constituye una función pública que se integra en una perspectiva de la Unión Europea. Desde el Tratado de Ámsterdam de 1997, entre los objetivos principales de las instituciones comunitarias se encuentra el desarrollo equilibrado, armónico y sostenible del territorio, dado el significativo impacto espacial de numerosas políticas sectoriales supranacionales como la libre competencia, a la regulación de los fondos estructurales y de cohesión o la política agrícola común. Entre los instrumentos de cooperación de la política de ordenación territorial europea destaca la Red Europea de Observación sobre cohesión y desarrollo territoriales (antiguo Observatorio en Red para el Desarrollo Territorial Europeo -ESPON), un programa de cooperación en el que participan los 28 Estados miembros y otros países asociados como Noruega, Suiza, Islandia y Liechtenstein, y cuyo objetivo es aumentar el conocimiento sobre las estructuras territoriales, las tendencias y los impactos de las políticas en el territorio europeo, y asî̉ apoyar el desarrollo de las políticas europeas, nacionales y regionales y contribuir a formar una comunidad científica sobre el desarrollo territorial europeo.

En este sentido, y si bien el gobierno español asume la importancia de los Principios de Smart Regulation para la mejora del marco normativo, las líneas definitorias de la ordenación territorial y urbanística son fijadas por las Comunidades Autónomas y algunos entes locales con competencias territoriales por lo que dicha concertación es esencial para garantizar la seguridad jurídica de los ciudadanos y de los agentes sociales y económicos.

Como declara la STC 28/1997 "hemos advertido que dentro de este ámbito material no se incluyen todas las actuaciones de los poderes públicos que tienen incidencia territorial y afectan a la política de ordenación del territorio. De la multiplicidad de actuaciones que inciden en el territorio se sigue la necesidad de articular mecanismos de coordinación y cooperación (STC 149/1991), pero no su incorporación automática a la competencia de ordenación del territorio". Por ello, el ente 
competente en esta materia, al ejercer la actividad ordenadora, estableciendo los instrumentos de ordenación territorial y urbanística, deberá respetar las competencias ajenas que tienen repercusión sobre el territorio, coordinándolas y armonizándolas desde el punto de vista de su proyección territorial. El ejercicio de la competencia sobre ordenación territorial resultará, pues, condicionada por el ejercicio de esas competencias que afectan al uso del territorio; sin embargo, desde estos ámbitos competenciales no podrá llevarse a cabo una actividad de ordenación de los usos del suelo. Como ya dijo el Tribunal Constitucional en la STC 149/1991 "para que este condicionamiento legítimo no se transforme en usurpación ilegítima, es indispensable ... que el ejercicio de esas otras competencias se mantenga dentro de los límites propios, sin utilizarla para proceder, bajo su cobertura, a la ordenación del territorio en el que han de ejercerse. Habrä que atender en cada caso a cuál es la competencia ejercida por el Estado, y sobre qué parte del territorio de la Comunidad Autónoma opera, para resolver sobre la legitimidad, o ilegitimidad".

\section{CONSIDERACIONES PREVIAS A LA ELEGCIÓN DEL MODELO TERRITORIAL}

A la luz de las previsiones de crecimiento demográfico para 2050, el compromiso de los gobiernos de las grandes ciudades con la sostenibilidad es imprescindible. En apenas tres décadas, la población mundial (situada ahora en 7.500 millones de habitantes) se incrementará en dos mil millones más, lo que implica una enorme presión adicional para el planeta. Según la OCDE, en un futuro próximo 70 de cada 100 personas en el mundo vivirán en grandes ciudades. Se estima que emplearemos un $80 \%$ más de energía, lo que podría conllevar un incremento del $70 \%$ en las emisiones de C02. Para que esto no ocurra, es necesario un cambio de mentalidad integral por parte de las administraciones públicas, las empresas y la población.

El concepto de ciudad sostenible (vinculado al Objetivo de Desarrollo Sostenible número 11 de Naciones Unidas ${ }^{23}$ ) está basado en tres pilares fundamentales. El primero de ellos es el social, que incluye todos aquellos factores relacionados con la calidad de vida de la población, desde el acceso a la educación y la sanidad hasta los índices de criminalidad, el coste del alquiler o el del precio de la cesta de la compra. El segundo hace referencia a las cuestiones medioambientales: el grado de polución, el uso de energías renovables, la disponibilidad de zonas verdes, el éxito de las políticas de reciclaje, etc. El tercer pilar de la sostenibilidad urbana es la fortaleza de la

23 Objetivos de Desarrollo Sostenible (ODS) establecidos para el periodo 2016-2030 dentro de la Agenda 2030 para el Desarrollo Sostenible acordada en la Asamblea General de la ONU del 25 de septiembre de 2015. 
economía, cuyos índices serían la renta per cápita, la tasa de empleo o la calidad de las infraestructuras de transporte.

Según estos criterios, una ciudad sostenible sería aquella capaz de autoabastecerse de energía y con capacidad para reutilizar sus residuos como materias primas, que garantizase el acceso a viviendas seguras, asequibles y accesibles para todo tipo de personas y que se rijan por principios ecológicos, formativos y de igualdad.

Todo ello a través de políticas que fomenten nuevas formas de movilidad urbana más ecológicas y sostenibles o la construcción de las denominadas "Edificaciones Eficientes", que tienen en cuenta todas las características climáticas y paisajísticas del sitio donde se quiere construir, como la dirección de los vientos, la radiación solar o los materiales locales.

El diseño de ciudades más verdes y compactas que logren un equilibrio urbano entre los espacios dedicados a la funcionalidad y la organización urbana y aquellos espacios orientados al ciudadano, a la tranquilidad y al contacto con la naturaleza es uno de los objetivos a tener en cuenta con carácter previo a la tramitación de cualquier planificación territorial o urbanística. Los espacios públicos dan identidad a los barrios y son vitales para la creación de comunidad y la mejora de la calidad de vida y, según el Banco Mundial, un desarrollo más compacto tiene beneficios directos sobre las emisiones de carbono y la longitud de las tuberías o las carreteras. En otras palabras, este tipo de urbanismo aumenta la eficacia del transporte al acortar los trayectos, lo que a su vez reduce la contaminación del aire.

De otro lado, la Unión Europea propone una transición hacia sistemas de gestión de residuos basados en la economía circular; es decir, aquella que trata de reducir residuos y facilitar el reciclaje para convertirlos de nuevo en materia prima. Asimismo, propugna tener más en cuenta la opinión de los ciudadanos en las elecciones del modelo de ciudad. Las administraciones deben poner en marcha sistemas de participación pública (independiente de las elecciones autonómicas y locales) para implicar a los contribuyentes en la mejora de su entorno.

La Administración local o regional, con carácter prévio al diseño e implementación de las políticas de desarrollo urbanístico o territorial más adecuadas, ha de disponer de un análisis y diagnóstico previo que refleje tanto las fortalezas y debilidades como las alternativas de desarrollo y la viabilidad económica, y sólo entonces, una vez conocidos los factores que pueden llegar a influir en la elección del modelo de ciudad, adoptar la solución que mejor se integre en el territorio.

No sólo es necesario tener en cuenta la existencia de recursos naturales y su tipología, sino también estudiar aquellos recursos sobreexplotados, aquellos que se encuentren sin explotar y que puedan proporcionar potencialidades productivas, y 
aquellos que, a través de valores medioambientales, paisajísticos y/o monumentales, puedan transformarse, a los efectos de ampliar y potenciar el desarrollo económico de la zona.

A lo expuesto, hay que añadir que la base productiva del territorio define su carácter agrario, industrial o de servicios, siendo, por tanto, esencial conocer el tipo de actividades que predominan en la economía de la localidad.

También hay que considerar las infraestructuras y el equipamiento con los que cuenta el municipio ya que la accesibilidad es un factor que condiciona los procesos de desarrollo y de cambio estructural local.

Con respecto a las infraestructuras, en dicho concepto debe incluirse tanto las de carácter físico (transportes, urbanización, comunicación, etc. que determinan la accesibilidad del municipio y la atracción para la localización de actividades) como aquellas infraestructuras denominadas intangibles (y que permiten acceder mediante nuevas tecnologías a proveedores y clientes en el resto del mundo, introducirse en redes a escala internacional, desarrollar innovaciones y aplicarlas, o acceder a ellas).

El estudio previo del modelo de ciudad deberá definir, por tanto, las estrategias a desarrollar para la obtención u optimización de dichas infraestructuras, incluida, en aquellos casos en los que la actividad industrial sea o se prevea importante en la economía del municipio, el diseño de zonas industriales locales o supralocales, con una oferta de servicios que sea atractiva para la implantación de empresas e iniciativas exógenas.

Resulta obvio que las políticas de ordenación del territorio y de urbanismo han venido evolucionando conforme a los cambios sociales y económicos producidos a nivel mundial y que no siempre esa evolución ha respetado los principios definidos en el concepto de Smart Regulation.

Afortunadamente, se va tomando conciencia de que el Estado del Bienestar no sólo supone consumo e inmediatez. El bienestar real parte de la consideración de un desarrollo sostenible basado en una relación equilibrada y armoniosa entre las necesidades sociales, la economía y el medio ambiente.

Ese desarrollo sostenible implica, a su vez, el análisis de cada región desde la perspectiva del refuerzo de sus recursos endógenos. No existe un único modelo de ciudad a la hora de decidir la planificación urbanística de una región, porque cada región tiene sus propios signos distintivos, bien sea por factores sociales, económicos, culturales, o paisajísticos.

Por ese motivo, la planificación urbanística de un territorio debe evitar la imposición de políticas territoriales que no hayan sido previamente estudiadas, consen- 
suadas y motivadas. No sólo porque el fracaso de una actuación urbanística o de un modelo de ciudad impuesto sin justificación supone una pérdida de oportunidades prolongada en el tiempo (dado que la "vida" de un instrumento de planificación urbanística puede llegar a 20 años) sino porque los recursos económicos, sociales y políticos aplicados a un modelo destinado al fracaso no sólo suponen una merma en la calidad de vida de los habitantes de la zona. También significa destinar unos recursos y fondos públicos a un proyecto que, de antemano, se prevé ineficaz.

A pesar del control jurisprudencial, ejemplos de esto último han provocado una gran alarma social estos últimos años y, no hay que ser experto en derecho urbanístico ni analista económico para comprender que cualquier planificación o actuación que afecte a la totalidad de un territorio debe ser viable económicamente y debe contar con el apoyo de la ciudadanía y de todas las administraciones y organismos públicos y privados existentes. Ello no significa que la política urbanística o el modelo de ciudad que se elija sean inamovibles, por cuanto la evolución y el desarrollo de un modelo de ciudad pueden dar lugar a la necesidad de considerar opciones que, en un primer momento no fueron tenidas en cuenta. Si bien esa mejora en el modelo de ciudad debe ser estudiada previamente, motivada, documentada y aprobada por los organismos competentes, también es cierto que los mecanismos para su implantación deben ser flexibles y, cuanto menos, ágiles, ya que la demora en la tramitación administrativa de los mismos puede suponer la pérdida de oportunidades para la región.

Por lo expuesto, es indiscutible que el concepto de Smart Regulation es un elemento esencial a la hora de definir la política urbanística de un territorio pero, sobre todo, a la hora de garantizar la identidad de sus habitantes y la idoneidad de dicho territorio para la implantación de empresas relacionadas con actividades económicas predominantes y/o subsidiarias.

De este modo, el desarrollo urbanístico de un municipio está estrechamente vinculado al desarrollo económico y a la valoración de las peculiaridades paisajísticas, culturales y sociales existentes. Cualquier actuación que pretenda la diferenciación o exclusión de alguno de estos elementos está encaminada al fracaso del modelo de ciudad propuesto por cuanto es la conexión de todos estos factores lo que va a permitir un desarrollo urbanístico sostenible. 


\section{INVESTIGACIÓN BIBLIOGRÁFICA:}

AGENDA 2030 PARA EL DESARROLLO SOSTENIBLE. Asamblea General de la ONU. 25 de septiembre de 2015

BALSA, C., "La better regulation", en Papeles de Evaluación, núm. 1 (2006), Agencia Estatal de Evaluación y Calidad de las Políticas Públicas.

COMISIÓN EUROPEA, (2015). "Propuesta de Acuerdo lnterinstitucional sobre la mejora de la legislación". Comunicación de la Comisión al Parlamento Europeo y al Consejo. Comisión Europea, Bruselas, Bélgica, 19 de Mayo de 2015.

COMISIÓN EUROPEA, (2010). "Smart Regulation in the European Union". Comunicación de la Comisión al Parlamento Europeo, al Consejo al Comité Económico y Social y al Comité de las Regiones. Comisión Europea, Bruselas, Bélgica.

FERNÁNDEZ DÍEZ-PICAZO, M. y MATEO FEITO, M. "Evaluación de Impacto Normativo en España”, en Presupuesto y Gasto Público, núm. 68 (2012).

GUTIÉRREZ COLOMINA, V. "Estudio jurisprudencial sobre los efectos de la nulidad del planeamiento de ordenación del territorio y urbanístico de Andalucía", en Territorio y Urbanismo, 2017, CIVISUR.

JACOBS, J., The Economy of Cities, trad. cast. La economía de las ciudades, Edición 62, 1969.

KONZENDORF, G., WORDELMANN, P., BÖLGK, S. Y VEIT, S, “Milestones on the way to Better Regulation at the European Union Level", estudio realizado para la 44 reunión de Directores Generales responsables de las Administraciones Públicas de los Estados miembros de la UE, Luxemburgo, Junio 2005.

MONTIN, C. H., "La Smart Regulation nell'Unione Europea". En F. BASILICA Y F. BARAZZONNI, Verso la Smart Regulation in Europa/Towards Smart Regulation in Europe, Maggioli Editori, 2013.

OCDE (2009). "Regulatory Impact Analysis A Tool for Policy Coherence". Reviewes of Regulatory Reform.

OCDE (2010). "Better Regulation in Europe: Spain 2010". En colaboración con la Comisión Europea.

PENSADO SEIJAS, A., "Administración electrónica y simplificación administrativa en las Administraciones Públicas: Nuevas medidas y especial incidencia en materia de actividades económicas", en Revista digital CEMCI, núm. 26 (2015).

SUBDIRECGIÓN GENERAL DE ORDENAMIENTOJURÍDICO-ECONÓMICO, Dirección General de Política Económica, Ministerio de Economía y 
Hacienda (2011): "Hacia una regulación económica más inteligente". Boletín de Información Comercial Española.

VVAA, Reforma del Régimen Local: La Ley de Racionalización y Sostenibilidad de la Administración Local: veintitrés Estudios, Editorial Aranzadi, 2014.

VVAA, "Informe al Presidente de la Comisión Europea", Grupo Operativo sobre Subsidiariedad, Proporcionalidad y "Hacer menos pero de forma más eficiente". 10 de Julio de 2018. 